Article

\title{
Online Education Program in Operational Meteorology and a Case Study about a Product for Decision Making
}

\author{
Marcial Garbanzo-Salas *(D) and Diana Jimenez-Robles \\ School of Physics, University of Costa Rica, San Pedro Montes de Oca 11501, Costa Rica; \\ diana.jimenezrobles@ucr.ac.cr \\ * Correspondence: marcial.garbanzo@ucr.ac.cr
}

Received: 4 January 2020; Accepted: 20 February 2020; Published: 16 March 2020

check for updates

\begin{abstract}
An online program developed at the University of Costa Rica provides the professionals working in meteorology a new way to pursue graduate level degrees. The focus of this graduate program is Operational Meteorology and the students need to complete the research and development process of an operational product to graduate. The products created during the program are a solution to operational institutions in need of innovation and can later be incorporated into institutional activities including advisories, warnings and emergency management. A case study included here shows an example of the need that led to the product, the methodologies used for the development and the final operational product created.
\end{abstract}

Keywords: distance education; online program; operational meteorology; Central America

\section{Introduction}

In Central-American Countries it is common that graduates from the meteorology programs move into positions at different institutions instead of pursuing higher education. Other professions in that and other regions can suffer the same fate as economic reasons are behind such behavior [1]. It is unlikely for meteorologists to allocate the appropriate amount of time and resources to enter a full time graduate program. In a regional assessment most meteorological services indicated that sending meteorologists to be trained in a two year period was not possible as they need their presence to support operational activities. Due to the load of administrative and operational tasks, research is minimized or not carried out in institutions dedicated to Operational Meteorology, complicating even further the academic advancement of employees. An online program in operational meteorology was needed in the region to contribute towards academic and professional training. The generation of applied research products that could be incorporated into operations is also a need.

The University of Costa Rica (UCR) is the largest research institution in Central America [2]. The activities of UCR are distributed among three main areas: teaching, research and outreach [3]. UCR is the largest educational institution in the country serving close to forty thousand students per year. The Department of Atmospheric, Oceanic and Planetary Physics (DFAOP in Spanish) has served as a Regional Training Center (RTC) for the World Meteorological Organization since 1969. UCR alumni can be found in meteorological services, academic institutions and the private sector in many countries in Latin America [3]. Some alumni are directly related to decision making activities.

Regarding the Costa Rican government, all weather warnings and advisories correspond to the National Meteorological Institute (IMN in Spanish). The entity that prevents and handles emergencies 
in Costa Rica is the National Commission for Risk Prevention and Emergencies (CNE in Spanish). IMN advises CNE on matters of atmospheric phenomena, its forecast and probable impacts. The proper training of meteorological personnel and active research on operational products is crucial in IMN's capacity to properly advise CNE. Most of the meteorological personnel (technical and professional) of IMN have been trained at UCR where the Center for Geophysical Research (CIGEFI in Spanish) and the Laboratory for Atmospheric and Planetary Research (LIAP in Spanish) are located. Research in atmospheric physics and hydrology is very active in CIGEFI and LIAP. Recently the Climate System Observation Laboratory (LOSiC in Spanish) was created to support research projects in areas related to applied meteorology.

In this article a master's level degree in Operational Meteorology will be introduced as a solution for graduate level education and research in Operational Meteorology products. A short view of online teaching at UCR and its current status is included for completeness. A case study that combines satellite imagery and surface weather station information to locate areas of probable effects due to precipitation will also be presented. This case study is presented as the product development was carried out by an IMN forecaster and is already implemented in operations at IMN.

In the next section the general aspects of the graduate programs in meteorology at the UCR will be covered. Section 3 covers the aspects of online teaching at UCR and the impacts on the Operational Meteorology online program. In Section 4 the case study is presented including the process and methodology used with the student that led to the generation of an operational product. Section 5 contains the recommendations and best practices. At the end the conclusions of the process that led the student to the success of moving into operations will be stated.

\section{Graduate Program in Operational Meteorology}

The School of Physics (UCR) offers an undergraduate program in meteorology and holds different graduate programs. Due to a need in the region an online program in Operational Meteorology was created in UCR. The online program in operational meteorology is part of several graduate programs hosted by the School of Physics. There are in total four different programs leading to a master degree, three of these are academic programs in Physics, Atmospheric Science and Hydrology. The fourth program is an online professional program oriented towards Operational Meteorology. This program serves the region and students from all countries are welcomed. Funding for students is not available in UCR, however, several grants can be found in the region to contribute towards the costs.

The main objective of the online program is to train professional meteorologists in operation and administration of National Weather Services (NWS) to be capable of dealing with theoretical and applied aspects of meteorology. In his article, Baum [4] indicates the importance of the collaborative work between the university and the meteorological services in the virtual programs for training meteorologists. Indicating that the participation of students in meteorological services, while they are developing their studies, allows them to acquire skills on political, administrative and procedural aspects needed in their professional performance. In addition, other institutions dedicated to the education in meteorology have promoted the importance of joint work between universities and weather services. That is the case of the Cooperative Program for Operational Meteorology (COMET). They started, in 1997, the virtualization of their training and courses with the creation of MetEd (virtual competency-based courses), emphasizing the need to reach more people and to strengthen the relationship between what was learned academically and its implementation [5]. The results obtained from MetEd have been presented by Dills et al. [6]. More recently, the Applied Remote Sensing Training (ARSET) program of the National Aeronautics and Space Administration (NASA) has contributed to train specifically in the area of remote sensing [7]. 
The students joining our online program already hold a position in an institution (e.g., IMN). Graduate students usually have relevant interests to pursue during the final part of the online program. The final graduation project (FGP) needs to be oriented towards an operational aspect of meteorology or a related area. Students from different areas of science can enter the program although some leveling courses might be required depending on the individual's background. Among the leveling courses are several introductory courses on physics, mathematics, statistics, meteorology and hydrology. A two week workshop on online learning systems is required for all students before starting the program. The Operational Meteorology online program includes courses in the physical foundations of meteorology, oceanography, climatology, hydrology, meteorological instrumentation and information, as well as administrative courses on international relations, management accounting and environmental administration. Students enrolled in the program need to dedicate a minimum of five to six hours a day (a total of 1800 to $2160 \mathrm{~h}$ ) to study the materials and carry out activities.

The first generation of students started the program in 2017. The countries of origin of these students are Colombia, El Salvador, Mexico and Costa Rica. Some students were removed from the program early on because even when they met the requirements the load of courses and activities was much higher than they anticipated. Most students continued successfully with half of them already graduated and the other half will graduate in early 2020, for a total success rate of $73 \%$. It is worth remarking that all the students in this program were already associated with an institution and working in Operational Meteorology.

\section{FGPs and Operational Products}

Every institution has a need to develop research activities and operational products. These needs can cover a plethora of areas in a NWS, including (but not limited to) administration, management, research and development, information technologies and forecasting products. As already mentioned, all students had positions in an institution and they brought to the program the identified needs from their respective institutions. These needs served the staff as a launching platform to look for topics that could satisfy the program's goals and at the same time to provide the individual/institution with the desired product.

During the last stage of the program, once the student narrows down the area of interest and desired product, a supervisor is assigned to guide the process. Two reviewers are also involved in the process and can be either UCR personal or external experts in the area. In some cases, other UCR students can be part of the process and act as research/development assistants as will be shown in the case study later. Having a strong collaboration among the group of experts and the students is key to the student's success, especially in an online program where students can feel isolated and distant to the institution [8].

To provide some perspective on the areas chosen for the student's FGPs, a list of the titles is presented in Table 1. The country of origin of the students is also included in Table 1 . The projects are oriented in different areas of Operational Meteorology, relevant to the students' institutions. Some projects are focused on case studies of extreme events that affected their respective country. Other projects are more inclined towards numerical weather and climate prediction tools, some on verification and others on evaluation. The importance of these projects is that one way or another, an operational need was investigated and a product was generated to satisfy such need.

To exemplify further, three final graduation projects out of those presented in Table 1 are mentioned in short. First, a student from IMN carried out an investigation on variability of the Standardized Precipitation Index (SPI) using different automatic weather stations in Costa Rica. This investigation has served IMN to identify dry and rainy years, study the behavior of SPI for different regions, study the relationship of ENSO and SPI during 1981 to 2010, among others. 
Second, a student from the National Meteorological Service (SMN in Spanish) of El Salvador studied the intense electrical storms that led to lightning strikes in the Metropolitan area of the capital city between 2015 and 2017. Satellite and radar data were incorporated in the study along with automatic weather station information and aeronautical reports. The impact caused by individual events was considered during the analysis. According to a private communication from the project director, the results of this final graduation project have been incorporated into operations as an important asset.

As a third and final example of other final graduation projects, a case from a Mexican student is mentioned. The student's research was focused on simulating the storm surge generated by Hurricane Karl in 2010 in Veracruz, Mexico. The results of the simulation were compared to observations and reports of the hurricane's impact. The research results can now be used in operations to establish operational parameters to be expected during hurricane season and possible impacts according to operational simulations.

Table 1. In this table the titles of the FGPs for the first generation of students is presented. The country of origin of the student is shown in the left column. It is important to remark that the titles are originally in Spanish and were translated to English for this article.

\begin{tabular}{|c|c|}
\hline Country of Origin & Final Graduation Project Title \\
\hline Mexico & Effects of storm surge caused by Hurricane Karl (2010) \\
\hline Mexico & Objective climatology of cold front passes in Mexico: 1979-2017 \\
\hline El Salvador & $\begin{array}{l}\text { Verification of rain forecast performance during a tropical wave on El Salvador } \\
\text { using different cumulus physics in WRF model }\end{array}$ \\
\hline El Salvador & $\begin{array}{l}\text { Characterization of intense storms that caused impacts in the metropolitan area of } \\
\text { San Salvador, El Salvador, in the years 2015-2017 }\end{array}$ \\
\hline Costa Rica & $\begin{array}{l}\text { Application of the normalized precipitation index to study droughts in Costa Rica } \\
\text { in the period 1981-2010 }\end{array}$ \\
\hline Costa Rica & $\begin{array}{l}\text { Evaluation of the seasonal forecast of rain using the CFS model during the winter } \\
\text { of the northern hemisphere }\end{array}$ \\
\hline Costa Rica & Analysis of the images of GOES-East for Costa Rica during tropical storm Nate \\
\hline Costa Rica & $\begin{array}{l}\text { Application in short term forecast of the Costa Rican lower troposphere variability } \\
\text { aspects based on meteorological sounding data }\end{array}$ \\
\hline
\end{tabular}

\section{Online Teaching at UCR}

Since the advent of virtual learning environments (VLE), universities have been working on the proper implementation of such systems in their academic activities. That is the case of the universities in the United States [9] where, in the fall of 2012 around 6.7 million higher education students were enrolled in online courses. That number has been increased since, because online programs became a strategy to reach more people and a way to take advantage of the developments in technology applied to education. UCR has been working on the proper implementation of such systems in its academic activities. At UCR, the first step was to implement a version of Modular Object Oriented Dynamic Learning Environment (Moodle) - a platform that integrated different modules (assignments, activities, evaluations) and other resources that can be uploaded to the course as documents, videos, web sites, among others [10]. This implementation allowed the specialist to evaluate and understand its capabilities and benefits in higher education. A lesson learned from the evaluations was that even when technology provides new ways of teaching, it is not enough by itself. UCR decided to customize the software and complement it with a new department. The new department's name is Support Unit to Teaching using Information and Communication Technologies (METICS [11] in Spanish) and is dedicated to supporting 
the online learning tool and the proper training of educators and students. As a functionality factor, the tools offered by Moodle are effective in the teaching-learning process in the university environment as long as they are well managed [10]. METICS provides educational resources (videos, documents, online and face-to-face workshops) to build the capacity of teachers and students on how to properly utilize the platform.

The role of METICS and the online teaching platform is not limited to its original goal. It has evolved with time and now is part of a wider strategy to improve education. The permanent staff at higher education institutions is usually trained in very specific areas (e.g., Physics and Meteorology) and education might not be part of their background. METICS provides UCR with a teaching/learning environment where innovation and self improvement is shared among the participants. In such a way, personnel from different backgrounds are continuously being exposed to better practices, resources and didactic strategies. The online programs at UCR have greatly benefited from the improvements made by METICS and the Operational Meteorology program is not an exception.

\section{Methodologies}

From the methodological point of view, the online program in Operational Meteorology represented a challenge for the DFAOP. Most of DFAOP's personnel have been trained in online teaching and participated in other programs and learning activities; nevertheless, this was their first time being in charge of an entire graduate program. It was necessary to redefine the roles undertaken by teachers and students, as well as the way of creating learning resources, the dynamics of the teaching/learning process and evaluation. METICS provided the necessary training in technical aspects of Moodle. There is also a University Didactic mandatory course at UCR, where professors and lecturers can explore new techniques and methodologies, as well as tools to better interact with students for face-to-face and online courses. The new tools and techniques complemented the previous teaching experiences of DFAOP's professors.

Different methodologies were used to plan the courses of the program, some centered on collaborative learning, others on individual development of capacities and knowledge and others on active learning $[12,13]$. By using the active learning methodology, the learning process is centered around the student and requires commitment to their learning process. Such commitment is usually provided by mature students with a greater understanding of their role in the learning process. Having graduate students with interest in professional development allowed us to implement the active learning methodology in different courses of the program and especially in the FGPs.

In an online program, part of the teacher's role [14] is to mediate between the course contents and the students. In face-to-face courses this is usually carried out by providing materials and interacting with students in the class room. In online courses, providing materials needs to be complemented with didactic activities and clear instructions. In the Operational Meteorology program these activities included forums, case studies, video conferences, assignments, short projects, among others. The didactic activities were also used as a variety of assessment tools to better understand students' motivation and improvements. The evaluation activities included online tests, write-ups and laboratory reports.

Having the appropriate methodologies is important during the coursework of the program for the student's success. The methodology becomes even more crucial when the students enter the FGP stage as this can be challenging, especially in online programs. The methodology used during the FGP development needs to be defined according to the student's competencies. Such competencies can be complicated to define and could include time management and computer programming skills and even the level of interest in the topic chosen for the FGP. In the following section a case study is presented. 


\section{Case Study}

In this section a case study of the learning process that led to an operational meteorology product will be shown. As previously mentioned, the interests of the students, his/her institutional needs and the available research personnel at UCR are considered when choosing the FGP topic. In Costa Rica, IMN needed an operational product for identifying regions with probable intense precipitation. An IMN forecaster was a student in the Operational Meteorology online program and intended to create a product to satisfy IMN's need. In addition, there are researchers at CIGEFI with a background in remote sensing that could provide guidance to the student. IMN's forecaster chose to study the case of Tropical Storm Nate using satellite imagery and how to identify areas of probable intense precipitation. The products of such study could be later implemented operationally with real time data and incorporated into the forecaster's schedule, impacting directly on the population as it can be communicated to CNE to prevent or handle emergencies.

It is worth clarifying to the reader that there is limited availability of meteorological radars in the region. Similarly, satellite data is available in some countries, however, in general satellite data access in the region continues to be in need of improvement. A satellite derived product related to precipitation probability can have a positive impact for the Costa Rican population, especially during extreme events. There are Level-2 precipitation products generated with GOES-East information, but such products are usually distributed using satellite receivers, or high bandwidth Internet-based dissemination tools. Both solutions are unusual in Central American and Caribbean countries. In addition, the generation of a Level-2 products usually requires complicated algorithms that need inputs from many different channels as well as microwave information for validation/calibration as shown by Kuligowski et al. [15], Stenz et al. [16] and references therein. A simpler product that could be easily computed in a small weather office to minimize the required satellite channels, was pursued by the student. Such a product in intense precipitation could be implemented in other countries with similar conditions and needs. The product research and development needed to be carried out and Tropical Storm Nate (October, 2017) provided a relevant event that could be studied in depth using satellite data and verified using surface measurements.

Since the launch of GOES-R (now GOES-East) in 2016, the new generation of satellites has been providing valuable information of atmospheric events for the Americas. UCR was prepared to obtain, process and utilize this information since 2017 when it was used for the first time in several face-to-face courses. WMO's Satellite Data Requirements (SDR) Group (For more information visit the website https:/ / sdr.ucr.ac.cr/) has provided a great platform for satellite data availability, related training and as a source of collaborations in the region. The satellite data for Tropical Storm Nate was gathered as it developed thanks to the connectivity to Unidata's IDD Network that is available at UCR. The new satellite data format and the amount of information for the days before, during and after the event requires special considerations to be properly analyzed and later utilized by the students.

Satellite information needs to be complemented with surface measurements to verify and validate the derived products. Since 2016, the DFAOP has been working on developing customized meteorological instruments to be used in undergraduate courses. Such instruments have proven to be flexible, reliable and capable of carrying out research. This initiative's name is UCR's Weather Station (UCR-ESME in Spanish) and one of its achievements is an automatic weather station (AWS) with high temporal resolution (as low as $1 \mathrm{~s}$ in some cases). This AWS was utilized during Tropical Storm Nate to gather high temporal resolution information about precipitation that could later be related to satellite observations. These measurements were utilized extensively by the student during the development of the operational product to better understand the relationship between satellite observations and surface measurements.

The combination of information from GOES-East and UCR-ESME's AWS allowed us to have satellite information every $15 \mathrm{~min}$ and precipitation information every $10 \mathrm{~s}$. It is important to remark that 16 
different channels are available from GOES-East, and the student needed to understand the relationship between all these channels and the surface observations. Here is where the active learning methodology was used as certain actions, tasks and activities were given to the student to reinforce the learning process. Among those activities we should mention concept mapping (to reinforce the relationship between atmospheric physics, satellite observations and surface measurements), group discussions with peers and professors (to compare levels of understanding and comprehension), and guided practices with case study information to report on observations and analysis. As indicated previously, the methodology needs to match the competencies of the participants. As the graduate student's background did not include computer programming, Python language and Bash Shell scripting, an undergraduate research assistant was included in the graduate student's support system.

An active learning activity was used to show the relationship between satellite measurements and surface observation. This activity consisted of guiding the student from the big picture, to high detail and back to the big picture. The initial big picture was to introduce the student to all available channels using the Level-2 information (brightness for visible and near infrared channels, and brightness temperature for infrared channels) as shown in Figure 1a. Tropical Storm Nate's satellite imagery from previous days, the days of the events and the following days (regular conditions returned) were used in the activity. More than seven thousand images are needed to show these big picture events, so instead of using each individual image, high resolution videos per channel were prepared in order to observe the time evolution. This big picture provided the student with a general view of the event from the satellite perspective. The high detail was provided by gradually zooming into the region where the AWSs were located during the extreme precipitation events for specific times identified by the student in the big picture stage. Four different zoom levels were used for the satellite images as shown in Figure 1b.

The location of the available AWS provided the latitude and longitude necessary to extract the time series from satellite observations. This provided the student with 17 time series, one generated for each satellite channel (16 in total) and another series generated from precipitation measurements. An example of the figures utilized to contrast the time series is included as Figure 1c, where the precipitation time series (blue line) is shown along with the times series from channels 12 to 16 for the same location. More than 30 figures, similar to Figure 1c were used to verify the relationship at different locations in Costa Rica. This activity of comparing time series allowed the student to understand the relationship between the behavior of the different channels and surface measurements during Tropical Storm Nate. At this point it was clear for the student that there was a simple relationship between the values observed in some of the channels and the precipitation.

The final stage of the activity (going back to the big picture) was to use the new understanding of the information to derive an algorithm that allowed the creation of a new product about regions with probable extreme precipitation events. A very simple algorithm, requiring only two channels ( $4 \%$ of the total information from GOES16's ABI sensor), was created to generate a product that could highlight the regions where intense precipitation could be expected. This is where the final big picture comes in, as the student applies the algorithm to the satellite images and goes back to large scale to see the areas of probable precipitation. An example of the product is shown in the left pane in Figure 2. The algorithm generates what is commonly known as masks in satellite meteorology. This mask can be applied to any channel to obtain a derived product. For example, the right pane in Figure 2 shows the mask applied to channel 9 (Mid-Level Tropospheric Water Vapor Band), generating a product where the brightness temperature of the region satisfying the algorithm can be observed. Now we move on to the final aspect of incorporating this newly created product in operations at the student's institution. 
a)

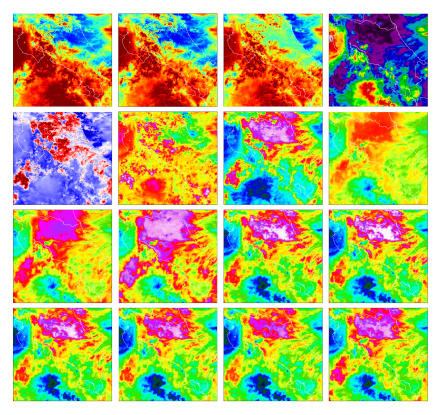

b)

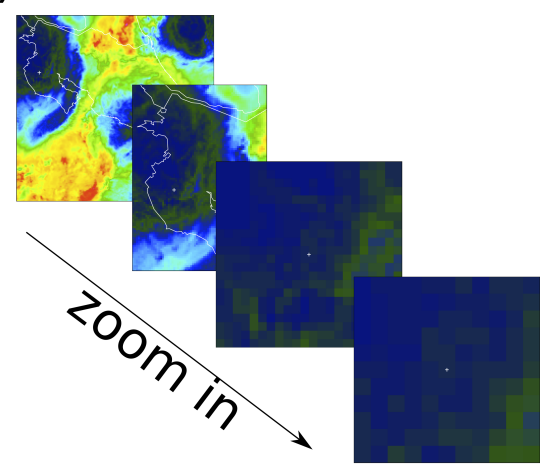

C)

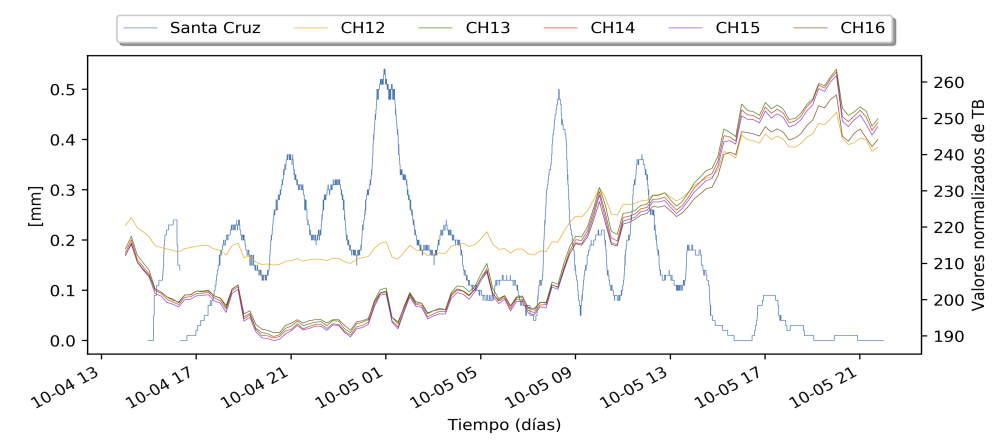

Figure 1. In this figure, some stages of a learning activity used during the FGP process are shown. (a) All 16 channels of GOES-East were animated in high resolution for a period of five days (prior to, during and after Tropical Storm Nate's effects). (b) Different zoom levels were used to bring the student from the big picture to the regional effects observed by the satellite. (c) One of the figures used by the student to contrast surface measurements of precipitation (blue line) and channel variation in time (other five lines) is included as an example of the educational resources. The titles are in Spanish as the products were developed in that language.
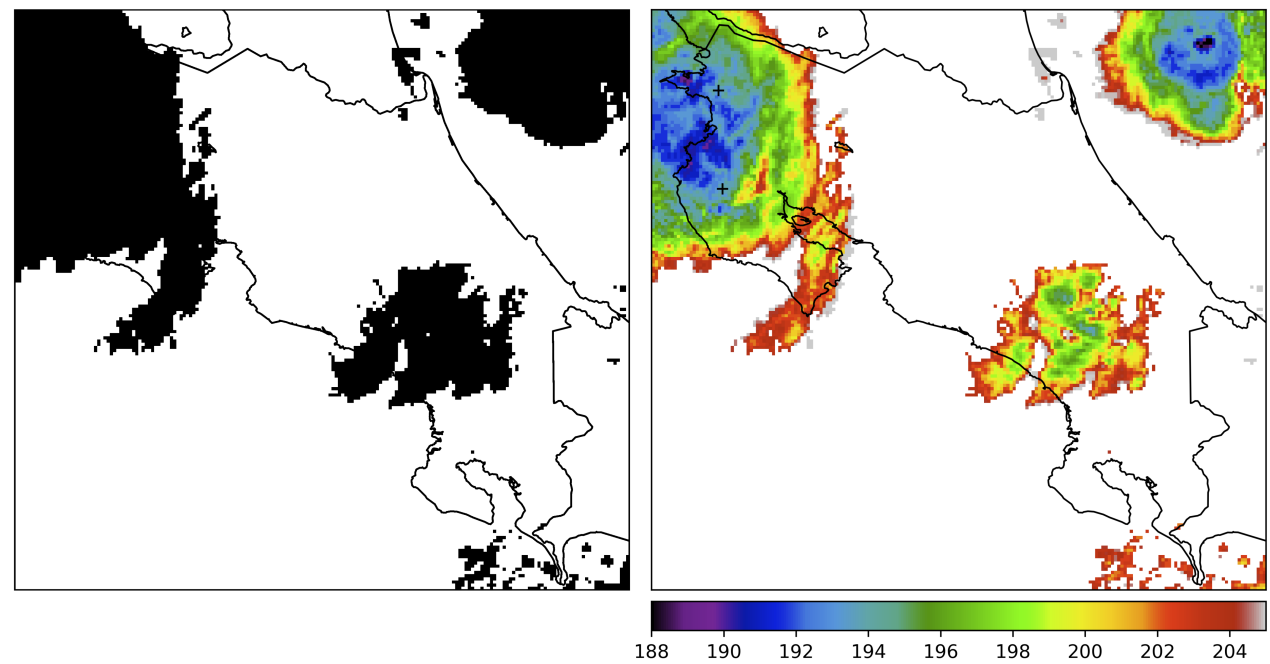

Figure 2. Left Pane. The black areas are generated by the student's algorithm and correspond to probable intense precipitation. Right Pane. The black areas were used as a mask and applied to Channel 9 to create a derived product useful to forecasters. 


\section{Employer's Perspective}

The previous case study showed the development of an algorithm used to create satellite products of probable areas with intense precipitation. The student who developed this algorithm and derived products was actively working for IMN. The working relationships allowed the students to apply their knowledge and concepts in controlled situations, as part of their professional training in meteorology [17], and consequently to inform the respective authorities of the developments and products as they were obtained. The director of the Synoptic Meteorology Department of IMN indicated (personal communication, 22 April 2019) that "This is the optimum way of developing new products for us! Many NWSs in the region have urgent needs of new/better tools and products specially for severe events. The participation of our employees in these online programs should be applauded and the generation of operational products should be a requirement". It is important to remark that the student who carried out the development shown in the case study is not the only IMN employee that completed the Operational Meteorology online program as two other IMN's forecasters completed the program too.

The director of the Synoptic Meteorology Department also mentioned the necessary steps for a product to be included in the forecaster's schedule and decision making process (including advising the Costa Rican government during emergencies). The required process is:

(a) The development of the new product needs to be communicated to the NWS authorities indicating that it has the potential to be included as an operational product in the department.

(b) Carry out initial product tests (defined by the Synoptic Meteorology Department).

(c) Send an official communication to the supervisor with formal information about the analysis of the new product.

(d) Request the implementation in the operational activities.

(e) Implementation in departmental activities.

(f) The product is included in monitoring and forecast.

(g) Further testing is carried out during rainy season.

(h) A publication is generated with the results.

At this moment the product is operational, meaning that it already passed stage $f$ of the process. The rainy season is about to end at the moment of writing this document and the testing period will take at least eight months.

\section{Recommendations and Best Practices}

It can be challenging for an institution to set up an online training program, especially a graduate program. The University of Costa Rica, and specifically the DFAOP has learned some lessons during this process. Some of these lessons have been compiled into recommendations that could help other institutions in the region to successfully create and deliver online programs in the area of operational meteorology:

(a) VLE support. The appropriate training of professors and students in a VLE is crucial for the success of any online program. Such training should not only focus on the technical aspects but include the student's capacities needed for the coursework and FGP. Having an office inside UCR dedicated to supporting online teaching, innovation and providing training was a key factor in the educational process presented in this paper.

(b) Prospect students. As it has been mentioned previously, the process of selecting students for the program was crucial in its success. In our case, the goal was to train professionals in meteorology while still working at their respective institutions. Highly motivated and mature students with a background in science and mathematics are ideal for a program of this kind. 
(c) Previous training. Before the beginning of the program all students and professors should be trained appropriately in the utilization of the VLE. The training should be carried out by experts in the area of online teaching and e-learning. In our case METICS (Section 3) provided the needed training and support. If suggested by the graduate program committee, the students should also take courses in other areas (e.g., mathematics, physics, fluid dynamics) to complement the VLE training and better prepare them for the graduate program.

(d) FGP process. The selection of the FGP needs to be a well coordinated task between professors, students and operational institutions. Strong and continuous interaction between the supervisor, advisors, support team and the student are crucial for the success of the FGP. Utilization of chat communication on an as-needed basis, weekly exchange of emails and occasional phone calls can be of great benefit during the final stage of the program.

(e) Keep operations in mind. The operational focus of the program should be considered from the planning stage to the completion of the FGP. An online program of this nature needs to keep an operational focus, mainly (not limited to) in the curriculum contents, teaching and evaluation methodologies, learning activities design and research products. This way, the optimum operational results will be a consequence of the natural development of activities.

\section{Conclusions and Future Developments}

The new online program at UCR provides a solution to several needs in the Central American region. This program provides an opportunity for meteorologists and other professionals to pursue a graduate level degree without leaving their current positions in operational institutions. Towards the end of the program, the students researched and developed a new operational product as part of their FGP. The Operational Meteorology online program provided the students with the knowledge, guidance and research environment needed to carry out the development of a new operational product.

These new products were incorporated into operations at the corresponding institutions, providing innovations and solutions to problems that otherwise could still be waiting for the allocation of time and resources. Improvements in the methodology utilized in the educational process will be implemented in the following generations. The quantification of the product's impacts and user satisfaction should be part of the implementation process.

Graduates from the Operational Meteorology online program have acquired training in different areas needed to participate actively and efficiently in the operational environment in their respective institutions. Having a position in operational institutions allowed the program's students to have their research products incorporated immediately in operations and consequently, to have a direct impact in the region. In addition to the knowledge and capacities acquired during the program, students also learned about important aspects of Operational Meteorology, including administration processes, IT infrastructure, operational procedures and teaching/learning strategies. This knowledge and capacity allows the program's graduates to deliver better solutions and products in their everyday activities.

Regarding the case study, it is worth mentioning that the product obtained by the student satisfies the goal of simplicity as only two channels are required to obtain the locations of probable intense precipitation. Small institutions/countries with limited Internet connectivity could still be able to generate their own products and have more capacity of towards awareness, prevention and emergency response. The student that carried out the research shown in the case study is now capable of training other personnel on the physical foundation of the product as well as the interpretation of derived satellite products.

Author Contributions: Conceptualization, Marcial Garbanzo-Salas and Diana Jimenez-Robles; Investigation, Marcial Garbanzo-Salas; Methodology, Diana Jimenez-Robles; Supervision, Marcial Garbanzo-Salas; Writing-original draft, Marcial Garbanzo-Salas and Diana Jimenez-Robles; Writing-review \& editing, Marcial Garbanzo-Salas. All authors have read and agreed to the published version of the manuscript. 
Funding: The funds for this paper were provided by the University of Costa Rica.

Acknowledgments: Thanks to the current and previous directors of the Graduate Programs in Meteorology. Thanks to the Director of the School of Physics, Ralph García Vindas, for the continuous support to LIAP where most of the activities were carried out and LOSiC. Thanks to Meteorologist Anthony Segura García for the processing and visualization of satellite imagery and other information. Thanks to Maureen Fonseca Mora for processing satellite imagery and creating high resolution videos.

Conflicts of Interest: The authors declare no conflict of interest.

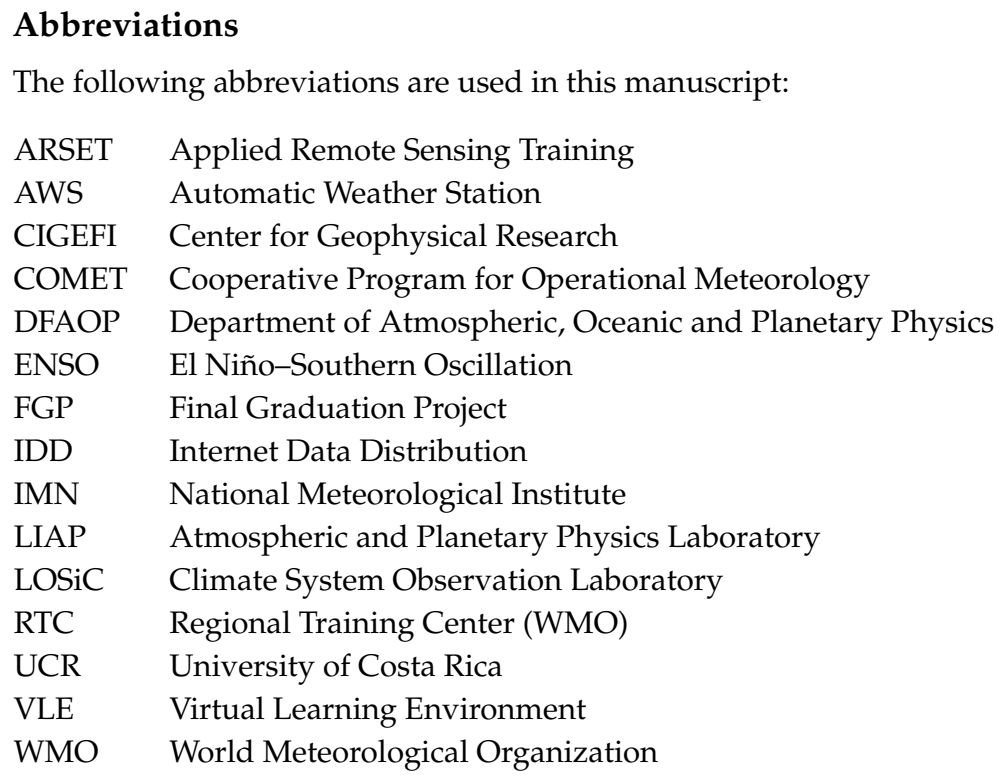

\section{References}

1. Moreno-Brid, J.C.; Ruiz-Nápoles, P. La educación superior y el desarrollo económico en América Latina. Rev. Iberoam. De Educ. Super. 2010, 1, 171-188.

2. Times Higher Education. Latin America Rankings. 2019. Available online: www.timeshighereducation.com/ world-university-rankings/2019/latin-america-university-rankings (accessed on 25 August 2019).

3. Alfaro, E.J.; Hidalgo, H.G.; Maldonado, T.; Pérez-Briceño, P.M.; Mora, N.P. A Tri-dimensional Approach to Climate Sciences. Caribb. Q. 2018, 64, 26-56. [CrossRef]

4. Baum, W.A. The roles of universities and weather services in the education of meteorological personnel. Bull. Am. Meteorol. Soc. 1975, 56, 226-228. [CrossRef]

5. Johnson, V.; Jeffries, R.; Byrd, G.; Schreiber-Abshire, W.; Page, E.; Muller, B.; Alberta, T. Celebrating COMET's 25 years of providing innovative education and training. Bull. Am. Meteorol. Soc. 2015, 96, 2183-2194. [CrossRef]

6. Dills, P.; Stevermer, A.; Mancus, T.; Guarente, B.; Alberta, T.; Page, E. COMET's Education and Training for the Worldwide Meteorological Satellite User Community: Meeting Evolving Needs with Innovative Instruction. ISPRS Int. J. Geo-Inf. 2019, 8, 311. [CrossRef]

7. Prados, A.I.; Carleton-Hug, A.; Gupta, P.; Mehta, A.; Blevins, B.; Schmidt, C.; Barbato, D.G.; McCullum, A.J.; Hook, E.; Podest, E.; et al. Impact of the ARSET Program on Use of Remote-Sensing Data. ISPRS Int. J. Geo-Inf. 2019, 8, 261. [CrossRef]

8. Ali, A.; T Smith, D. Comparing Social Isolation Effects on Students Attrition in Online Versus Face-to-Face Courses in Computer Literacy. Issues Inform. Sci. Inf. Technol. 2015, 12, 011-020. [CrossRef]

9. Kentnor, H.E. Distance education and the evolution of online learning in the United States. Curric. Teach. Dialogue 2015, 17, 21-34. 
10. Costa, C.; Alvelos, H.; Teixeira, L. The use of Moodle e-learning platform: A study in a Portuguese University. Procedia Technol. 2012, 5, 334-343. [CrossRef]

11. Chacón Ramírez, S. Acompañamiento docente: El quehacer de la Unidad METICS/Teacher support: The work of Unidad METICS. Actualidades Investigativas en Educación 2012, 12, 2-5.

12. Akınoğlu, O.; Tandoğan, R.Ö. The Effects of Problem-Based Active Learning in Science Education on Students' Academic Achievement, Attitude and Concept Learning. Eurasia J. Math. Sci. Technol. Educ. 2007, 3, 71-81. [CrossRef]

13. Jerez Yáñez, O. Aprendizaje Activo, Diversidad e Inclusión. Enfoque, Metodologías y Recomendaciones Para su Implementación; Ediciones Universidad de Chile: Santiago, Chile, 2015.

14. Tileston, D.W. Teaching Strategies for Active Learning: Five Essentials for Your Teaching Plan; Corwin Press: Thousand Oaks, CA, USA, 2006.

15. Kuligowski, R.J.; Li, Y.; Hao, Y.; Zhang, Y. Improvements to the GOES-R Rainfall Rate Algorithm. J. Hydrometeorol. 2016, 17, 1693-1704. [CrossRef]

16. Stenz, R.; Dong, X.; Xi, B.; Feng, Z.; Kuligowski, R.J. Improving Satellite Quantitative Precipitation Estimation Using GOES-Retrieved Cloud Optical Depth. J. Hydrometeorol. 2016, 17, 557-570. [CrossRef]

17. Etherton, B.J.; Arms, S.C.; Oolman, L.D.; Lackmann, G.M.; Ramamurthy, M.K. Using operational and experimental observations in geoscience education. Bull. Am. Meteorol. Soc. 2011, 92, 477-480. [CrossRef]

(C) 2020 by the authors. Licensee MDPI, Basel, Switzerland. This article is an open access article distributed under the terms and conditions of the Creative Commons Attribution (CC BY) license (http:/ / creativecommons.org/licenses/by/4.0/). 